\title{
Using tri-axial accelerometers to identify wild polar bear behaviors
}

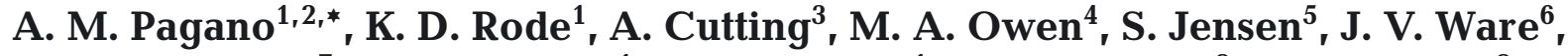

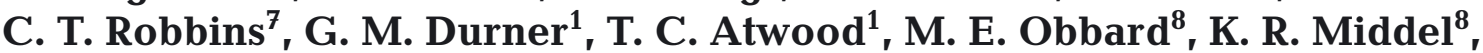 \\ G. W. Thiemann ${ }^{9}$, T. M. Williams ${ }^{2}$ \\ ${ }^{1}$ US Geological Survey, Alaska Science Center, 4210 University Dr., Anchorage, AK 99508, USA \\ ${ }^{2}$ Department of Ecology \& Evolutionary Biology, University of California, Santa Cruz, CA 95060, USA \\ ${ }^{3}$ Oregon Zoo, Portland, OR 97221, USA \\ ${ }^{4}$ Institute for Conservation Research, San Diego Zoo Global, San Diego, CA 92027, USA \\ ${ }^{5}$ Alaska Zoo, Anchorage, AK 99507, USA \\ ${ }^{6}$ Department of Integrative Physiology and Neuroscience, Washington State University, Pullman, WA 99164, USA \\ ${ }^{7}$ School of the Environment and School of Biological Sciences, Washington State University, Pullman, WA 99164, USA \\ ${ }^{8}$ Wildlife Research and Monitoring Section, Ontario Ministry of Natural Resources and Forestry, Trent University, \\ Peterborough, ON K9L 0G2, Canada \\ ${ }^{9}$ Faculty of Environmental Studies, York University, Toronto, ON M3J1P3, Canada
}

\begin{abstract}
Tri-axial accelerometers have been used to remotely identify the behaviors of a wide range of taxa. Assigning behaviors to accelerometer data often involves the use of captive animals or surrogate species, as their accelerometer signatures are generally assumed to be similar to those of their wild counterparts. However, this has rarely been tested. Validated accelerometer data are needed for polar bears Ursus maritimus to understand how habitat conditions may influence behavior and energy demands. We used accelerometer and water conductivity data to remotely distinguish 10 polar bear behaviors. We calibrated accelerometer and conductivity data collected from collars with behaviors observed from video-recorded captive polar bears and brown bears $U$. arctos, and with video from camera collars deployed on free-ranging polar bears on sea ice and on land. We used random forest models to predict behaviors and found strong ability to discriminate the most common wild polar bear behaviors using a combination of accelerometer and conductivity sensor data from captive or wild polar bears. In contrast, models using data from captive brown bears failed to reliably distinguish most active behaviors in wild polar bears. Our ability to discriminate behavior was greatest when species- and habitat-specific data from wild individuals were used to train models. Data from captive individuals may be suitable for calibrating accelerometers, but may provide reduced ability to discriminate some behaviors. The accelerometer calibrations developed here provide a method to quantify polar bear behaviors to evaluate the impacts of declines in Arctic sea ice.
\end{abstract}

KEY WORDS: Activity · Behavior - Polar bear · Ursus maritimus · Acceleration · Accelerometer · Brown bear $\cdot$ Ursus arctos

\section{INTRODUCTION}

Knowledge of an animal's behavior can inform species conservation and management by revealing how individuals respond to environmental conditions

${ }^{*}$ Corresponding author: apagano@usgs.gov
(Sutherland 1998, Caro 1999, Cooke et al. 2014). Although visual observation is the most direct method to study animal behavior, it is impractical for many species. Innovations in electronic logging and tracking devices have provided new methods to

(C) The authors 2017. Open Access under Creative Commons by Attribution Licence. Use, distribution and reproduction are unrestricted. Authors and original publication must be credited. 
study the behavior, movement, physiology, energetic rates, and environmental conditions of wildlife that may otherwise be difficult or impossible to monitor (Ropert-Coudert \& Wilson 2005, Cooke 2008, Wilson et al. 2008, Bograd et al. 2010, Costa et al. 2010, Wilmers et al. 2015).

Tri-axial accelerometers, which collect high frequency measures of acceleration in the form of gravitational and inertial velocity (Brown et al. 2013), have provided a means to remotely identify animal behaviors (Yoda et al. 1999, Watanabe et al. 2005). Accelerometers have been particularly useful in studying widely dispersed animals or those occurring in remote habitats, such as marine mammals and birds (Brown et al. 2013). Once calibrated, tri-axial accelerometer data from wild animals can be used to remotely identify behaviors such as resting, walking, running, and even feeding events (Yoda et al. 2001, Shepard et al. 2008, Wilson et al. 2008, Watanabe \& Takahashi 2013, Williams et al. 2014). Calibration typically involves time-synchronizing behavioral observations with their associated accelerometer readings, which often necessitates the use of captive animals or surrogate species (e.g. Yoda et al. 2001, Shepard et al. 2008, Nathan et al. 2012, Campbell et al. 2013). Alternatively, animal-borne video cameras can be used to directly calibrate accelerometers (e.g. Watanabe \& Takahashi 2013, Nakamura et al. 2015, Volpov et al. 2015), but cameras can be expensive and can only collect data over limited durations.

Polar bears Ursus maritimus typically occupy remote environments, and few quantitative data exist on their behaviors or activity budgets. Much of what is known about polar bear behavior on the sea ice comes from coastal indigenous resident knowledge (e.g. Nelson 1966, Kalxdorff 1997, Kochnev et al. 2003, Voorhees et al. 2014) and direct observational research limited to 2 locations over limited time periods (Stirling 1974, Stirling \& Latour 1978, Hansson \& Thomassen 1983, Stirling et al. 2016). Satellite telemetry has been used to track polar bears in some subpopulations since the late 1970s (Schweinsburg \& Lee 1982, Taylor 1986) and has helped to identify important habitats (Ferguson et al. 2000, Mauritzen et al. 2003, Durner et al. 2009, Wilson et al. 2014). However, detailed behavioral data in association with habitat conditions are lacking. Recent declines in Arctic sea ice have already caused declines in abundance, survival, or body condition of polar bears in some subpopulations (Stirling et al. 1999, Regehr et al. 2007, Rode et al. 2010, 2012, Bromaghin et al. 2015, Obbard et al. 2016) and models project increasing negative impacts in the $21^{\text {st }}$ century (Amstrup et al. 2008, Hunter et al. 2010, Molnár et al. 2010, Atwood et al. 2016). In order to better predict the impacts of projected sea ice loss on polar bears, it will be important to understand the behavioral and physiological mechanisms driving current declines (Vongraven et al. 2012, Atwood et al. 2016). Accelerometers could be used in combination with satellite telemetry to better understand the behavioral consequences of sea ice loss. This mechanistic information would allow for improved assessment of the relationships between habitat loss, individual health, and vital rates in polar bear populations.

In this study, we developed a method to quantify wild polar bear behaviors using accelerometers and conductivity sensor data, validated through animalborne video camera data. Additionally, we evaluated the effectiveness of using accelerometer data from captive polar and brown bears $U$. arctos to predict behaviors of wild polar bears. Though it is generally assumed that accelerometer signatures of captives or surrogates are similar to those of their instrumented wild counterparts (Williams et al. 2014, McClune et al. 2015, Wang et al. 2015, Hammond et al. 2016), this has rarely been tested. Captive individuals may exhibit different behaviors and/or kinematics than wild counterparts (McPhee \& Carlstead 2010), which could potentially influence accelerometer signatures. Because polar bears use both sea ice and terrestrial habitats and because differences in habitat substrate or gradient could also affect accelerometer signatures (Bidder et al. 2012, Shepard et al. 2013, McClune et al. 2014), we examined data from wild polar bears in both of these habitats. Lastly, because sampling frequency affects the longevity of accelerometers during deployment as well as computational power for analyses, we evaluated the ability of accelerometers to predict wild polar bear behaviors using 3 different sampling frequencies $(16,8$, and $4 \mathrm{~Hz})$.

\section{MATERIALS AND METHODS}

\section{Accelerometer recordings on captive bears}

We deployed collars with archival loggers (TDR10X-340D; Wildlife Computers) on 3 adult female polar bears Ursus maritimus housed at the Alaska Zoo, Oregon Zoo, and San Diego Zoo, USA, as well as 2 adult female brown bears $U$. arctos housed at the Bear Research, Education, and Conservation Center at Washington State University (WSU; Table 1), USA. Archival loggers recorded tri-axial acceleration (m $\mathrm{s}^{-2}$ ) at $16 \mathrm{~Hz}$ (range: $\pm 20 \mathrm{~m} \mathrm{~s}^{-2}$ ), time-of-day, and 
Table 1. Polar bears Ursus maritimus and brown bears $U$. arctos wearing collars with tri-axial accelerometers that were video recorded (captive bears) or that wore video-equipped collars (wild bears)

\begin{tabular}{|llccl|}
\hline Species & Sex & Age class & $\begin{array}{c}\text { Body } \\
\text { mass }(\mathrm{kg})\end{array}$ & Location \\
\hline Polar bear & Female & Adult & 288 & Alaska Zoo \\
Polar bear & Female & Adult & 212 & Oregon Zoo \\
Polar bear & Female & Adult & 237 & San Diego Zoo \\
Brown bear Female & Adult & 126 & Washington State University \\
Brown bear & Female & Adult & 126 & Washington State University \\
Polar bear & Female & Adult & 173 & Southern Beaufort Sea \\
Polar bear & Female & Adult & 176 & Southern Beaufort Sea \\
Polar bear & Female & Adult & 199 & Southern Beaufort Sea \\
Polar bear & Female & Adult & 172 & Southern Beaufort Sea \\
Polar bear & Female & Subadult & 141 & Southern Beaufort Sea \\
Polar bear & Male & Subadult & 186 & Akimiski Island \\
Polar bear & Female & Subadult & 140 & Akimiski Island \\
& & & & \\
\hline
\end{tabular}

wet/dry conductions (via an on-board conductivity sensor; Fig. 1). Conductivity data were sampled at $1 \mathrm{~Hz}$. Bears at the Oregon and San Diego Zoos were trained to voluntarily place their heads into crates in which collars could be applied or removed, and wore collars for 1 to $4 \mathrm{~h}$ sessions. Bears at the Alaska Zoo and WSU were anesthetized for collaring, with a combination of tiletamine $\mathrm{HCl}$ and zolazepam $\mathrm{HCl}$ (Telazol®; Pfizer Animal Health) and dexmedetomidine $\mathrm{HCl}$ (Dexdomitor®; Pfizer Animal Health) (Teisberg et al. 2014). Following collar placement, the effect of the anesthetic were reversed with atipamezole $\mathrm{HCl}$ (Antisedan®; Pfizer Animal Health). We used release mechanisms (Lotek Wireless) to remove collars from bears at the Alaska Zoo and WSU. We

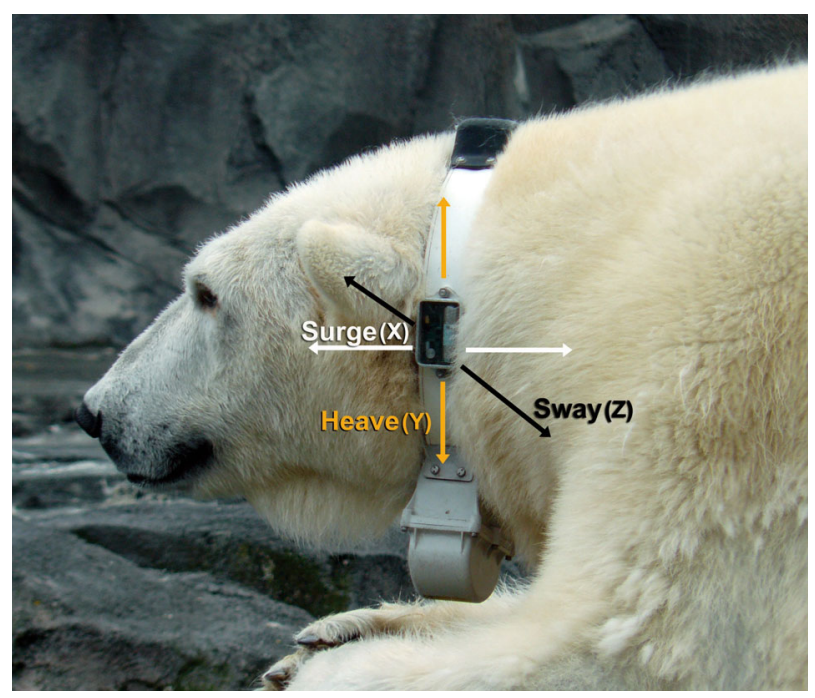

Fig. 1. Orientation of an archival logger containing a triaxial accelerometer attached to a collar for use on polar Ursus maritimus and brown bears $U$. arctos matched accelerometer recordings to the behaviors of captive bears while they moved freely around enclosures based on visual examination of timestamped video recordings (Sony camcorder model DCR-TRV280 or OpenEye Digital Video Security Solutions).

\section{Accelerometer recordings on free-ranging polar bears}

We deployed GPS-equipped video camera collars (Exeye) and archival loggers (TDR10-X-340D; Wildlife Computers) on 4 adult female polar bears and 1 subadult female polar bear captured on the sea ice of the southern Beaufort Sea in April 2014 and 2015 (hereafter 'ice bears') and 2 subadult polar bears (1 male and 1 female) captured on land on Akimiski Island, Nunavut, Canada, in September 2015 (hereafter 'land bears'; Table 1). Video collars, including archival loggers and release mechanisms, weighed 1.6 to $2.1 \mathrm{~kg}$ ( 0.8 to $1.5 \%$ of body mass of bears in this study). We captured polar bears by injecting them with immobilizing drugs through projectile syringes fired from a helicopter. On the sea ice, we anesthetized bears using a combination of tiletamine $\mathrm{HCl}$ and zolazepam $\mathrm{HCl}$ (Telazol@) with no reversal (Stirling et al. 1989). On land, we anesthetized bears with a combination of medetomidine (Domitor®; Pfizer Animal Health) and tiletamine $\mathrm{HCl}$ and zolazepam $\mathrm{HCl}$ (Telazol@) and reversed with atipamezole $\mathrm{HCl}$ (Antisedan®) (Cattet et al. 1997). Archival loggers were attached to collars in the same location and orientation as captive deployments (Fig. 1) and similarly recorded tri-axial acceleration at $16 \mathrm{~Hz}$ (range: $\pm 20 \mathrm{~m} \mathrm{~s}^{-2}$ ), time-of-day, and wet/dry conductions (via an on-board conductivity sensor). Conductivity data were sampled at $1 \mathrm{~Hz}$. Video cameras were programmed to record at varying frequencies during daylight periods (see Table S1 in the Supplement at www.int-res.com/ articles/suppl/n032p019_supp.pdf) and programmed to turn off if the temperature of the collar fell below $-17^{\circ} \mathrm{C}$ to protect video equipment. Collars deployed on ice and land bears were recovered 4 to $23 \mathrm{~d}$ following deployment, either by recapture of the individual or by remote activation of the collar release and retrieval of the dropped collar by the field crew. We matched accelerometer data to behavior of ice and land bears based on visual examination of the time-stamped video recordings from the collar. 


\section{Behaviors}

Behaviors were annotated based on the video data on a per second basis. For bears that were anesthetized, we excluded behaviors on the day of capture and during retrieval of the collar. Resting behaviors included standing, sitting, and lying down. Head movements while standing, sitting, or lying down were included as resting behaviors, but limb movements were treated as transitionary behaviors (Knudsen 1978, Williams 1983). Swimming included surface swimming and diving. We excluded from analyses any behaviors that were not indicative of natural movements in captive bears (e.g. stereotypic behaviors), were rare (e.g. fighting, breeding, drinking), were transitionary, or were non-descript.

\section{Modeling}

We derived summary statistics from the accelerometer data and linked the accelerometer data with corresponding behaviors of interest (SAS version 9.3; SAS Institute). We converted accelerometer measures from $\mathrm{m} \mathrm{s}^{-2}$ to $g\left(1 g=9.81 \mathrm{~m} \mathrm{~s}^{-2}\right)$. We calculated magnitude $(\mathrm{Q})$ as a fourth dimension, where

$$
\mathrm{Q}=\sqrt{\text { heave }^{2}+\text { surge }^{2}+\text { sway }^{2}}
$$

(Nathan et al. 2012). We used a 2 s running mean of the raw acceleration data to calculate static accelera- tion (gravitational acceleration) and subtracted the static acceleration from the raw acceleration data to calculate dynamic acceleration (Wilson et al. 2006, Shepard et al. 2008). We calculated overall dynamic body acceleration (ODBA) as the absolute sum of dynamic acceleration across the 3 axes (Wilson et al. 2006). We used a Fast Fourier Transform to calculate the dominant power spectrum (dps) and frequency (fdps) for each axis (Watanabe et al. 2005, ShamounBaranes et al. 2012). In total, we derived 25 predictor variables based on previous accelerometer studies (e.g. Watanabe et al. 2005, Nathan et al. 2012, Shamoun-Baranes et al. 2012, Wang et al. 2015). Predictor variables were extracted from the accelerometer data over $2 \mathrm{~s}$ intervals; mean conductivity data (wet/dry) was also extracted over $2 \mathrm{~s}$ intervals using program R (R Core Team 2014) (Table 2). Videolinked behaviors that lasted less than $2 \mathrm{~s}$ were excluded from analyses. We used a random forest supervised machine learning algorithm (Breiman 2001) in R ('RandomForest' package) to predict polar bear behaviors. Random forest models use multiple classification trees from a random subset of predictor variables and then replicate this process over multiple iterations using a subset of the data for each iteration to determine the best variables for making predictions (Breiman 2001). An estimate of error is derived by using the remaining data not used in each iteration to test the predictive ability of the model, which is termed the 'out-of-bag' (OOB) error rate

Table 2. Parameters extracted from tri-axial accelerometer and conductivity data and used in random forest models to predict wild polar bear Ursus maritimus behaviors. Respective acceleration measures from the surge (X), heave (Y), sway (Z), and magnitude $(Q)$ axes

\begin{tabular}{|c|c|c|}
\hline Parameter & Label & Definition \\
\hline Static acceleration $(g)$ & staticX, staticY, staticZ, staticQ & $\begin{array}{l}\text { Mean static acceleration along the surge, } \\
\text { heave, sway, and magnitude axes }\end{array}$ \\
\hline $\begin{array}{l}\text { Maximum dynamic body } \\
\text { acceleration }(g)\end{array}$ & mdbaX, mdbaY, mdbaZ, mdbaQ & $\begin{array}{l}\text { Maximum dynamic body acceleration along the } \\
\text { surge, heave, sway, and magnitude axes }\end{array}$ \\
\hline $\begin{array}{l}\text { Standard deviation dynamic } \\
\text { body acceleration }(g)\end{array}$ & stdbaX, stdbaY, stdbaZ, stdbaQ & $\begin{array}{l}\text { Standard deviation dynamic body acceleration } \\
\text { along the surge, heave, sway, and magnitude axes }\end{array}$ \\
\hline $\begin{array}{l}\text { Overall dynamic body } \\
\text { acceleration }(g)\end{array}$ & odbaX, odbaY, odbaZ, ODBA & $\begin{array}{l}\text { Mean dynamic acceleration body acceleration along } \\
\text { the surge, heave, and sway axes. ODBA = odbaX }+ \\
\text { odbaY + odbaZ }\end{array}$ \\
\hline $\begin{array}{l}\text { Dominant power spectrum } \\
\left(g^{2} \mathrm{~Hz}^{-1}\right)\end{array}$ & dpsX, dpsY, dpsZ, dpsQ & $\begin{array}{l}\text { Maximum power spectral density of dynamic accelera- } \\
\text { tion along the surge, heave, sway, and magnitude axes }\end{array}$ \\
\hline $\begin{array}{l}\text { Frequency at the dominant } \\
\text { power spectrum }(\mathrm{Hz})\end{array}$ & fdpsX, fdpsY, fdpsZ, fdpsQ & $\begin{array}{l}\text { Frequency at the maximum power spectral density of } \\
\text { dynamic acceleration along the surge, heave, sway, } \\
\text { and magnitude axes }\end{array}$ \\
\hline Mean wet/dry & wetdry & $\begin{array}{l}\text { Mean conductivity determination of whether the tag } \\
\text { is wet or dry (range: } 0-255 \text { ) }\end{array}$ \\
\hline
\end{tabular}


(Breiman 2001, Liaw \& Wiener 2002). The random forest algorithm has previously shown high accuracy $(>80 \%$ ) for predicting animal behaviors from accelerometer data (Nathan et al. 2012, Resheff et al. 2014, Graf et al. 2015, Lush et al. 2015, Rekvik 2015, Wang et al. 2015, Alvarenga et al. 2016). We fit 500 classification trees to each training dataset and used a random subset of 5 predictor variables for each split in the tree.

\section{Analyses}

Unbalanced datasets can bias the predictive ability of classification algorithms toward the most dominant classes (Chen et al. 2004). Therefore, we performed 3 initial analyses to test the effect of uneven distributions on predictive ability. The first analysis used an uneven distribution in which for ice and land bears, we randomly selected $70 \%$ of each behavior for the training dataset and used the remaining $30 \%$ to test the predictive ability of the random forest algorithm (e.g. Nathan et al. 2012, Alvarenga et al. 2016). For captive polar and brown bears we used the entire datasets to train the random forest algorithm. The second analysis used a subsampling approach in which we attempted to reduce the uneven distribution of more frequent behaviors (e.g. resting) in our training dataset. To reduce the uneven distribution of behaviors in the dataset from ice bears, we randomly selected $5 \%$ of the resting behaviors, 30\% of the walking behaviors, and $70 \%$ of each of the remaining behaviors for training the random forest algorithm. We used the remaining data from ice bears for testing predictions. To reduce the uneven distribution of the dataset from land bears, we randomly selected $5 \%$ of the resting behaviors and $70 \%$ of each of the remaining behaviors for training and used the remaining data to test predictions. To reduce the uneven distribution of the datasets from captive polar bears and brown bears, we randomly selected $10 \%$ of the resting behaviors, $30 \%$ of the walking behaviors, and $100 \%$ of each of the remaining behaviors for training the random forest algorithm. The third analysis used a completely balanced distribution in which we used identical sample sizes of 500 observations for each behavior in the training dataset and the remaining observations to test and excluded behaviors with less than 500 observations. Based on these 3 analyses, we used the sampling distribution (i.e. uneven, subsampled, or balanced distribution) with the greatest predictive ability for further analyses.
To evaluate our ability to predict behaviors of ice bears, we used 3 different datasets to train the random forest models and evaluated the ability of each of these models. First, we used a random subset of the data from ice bears as the training dataset and the remaining data from ice bears to test predictions (testing dataset). Second, we used the data from captive polar bears as the training dataset. Third, we used the data from captive brown bears as the training dataset.

To evaluate our ability to predict behaviors of land bears, we conducted 4 additional analyses. First, we used a random subset of the data from land bears as the training dataset and the remaining data from land bears to test predictions (testing dataset). Second, we used the training data from ice bears as the training dataset. Third, we used the training data from captive polar bears as the training dataset. Fourth, we used the training data from captive brown bears as the training dataset.

To examine the effect of sampling frequency on our ability to discriminate behaviors, we subsampled our $16 \mathrm{~Hz}$ accelerometer data to lower data acquisition rates of 8 and $4 \mathrm{~Hz}$ using SAS, and repeated the predictive analyses above for both ice and land bears.

Predicted behaviors were categorized as true positive (TP) if they correctly matched the actual behavior, true negative (TN) if they correctly identified as a different behavior, false positive (FP) if they incorrectly identified the behavior, and false negative (FN) if they incorrectly identified as a different behavior. We evaluated the predictive abilities of these models based on Matthews' correlation coefficient (MCC; e.g. Basu et al. 2013, Martins et al. 2016), the percent precision, recall, and F-measure. We used $\mathrm{MCC}$ in place of accuracy due to the unbalanced nature of our dataset.

$\mathrm{MCC}, \frac{\mathrm{TP} \times \mathrm{TN}-\mathrm{FP} \times \mathrm{FN}}{\sqrt{(\mathrm{TP}+\mathrm{FP}) \times(\mathrm{TP}+\mathrm{FN}) \times(\mathrm{TN}+\mathrm{FP}) \times(\mathrm{TN}+\mathrm{FN})}}$,

provides a measure of the agreement between the predicted and actual classifications, where +1 represents a perfect prediction and -1 represents total disagreement (Matthews 1975). Precision is the proportion of positive classifications that were correctly classified (TP/TP + FP), recall is the probability that a behavior will be correctly classified (TP/TP $+\mathrm{FN})$, and $F$-measure is the harmonic mean of precision and recall $(2 \times$ precision $\times$ recall/precision + recall $)$. We used 2 sample $t$-tests to evaluate whether MCC, precision, and recall differed significantly using a $16 \mathrm{~Hz}$ sampling frequency compared to either an 8 or 
$4 \mathrm{~Hz}$ sampling frequency based on the ice and land datasets.

\section{RESULTS}

\section{Behavior on the sea ice}

Video collars on ice bears Ursus maritimus recorded 14 to $55 \mathrm{~h}$ of video $(\bar{x}=38 \mathrm{~h}, \mathrm{SD}=17 \mathrm{~h}, \mathrm{n}=5)$. For predicting the behavior of ice bears, we collected a total of $140 \mathrm{~h}$ of video-linked accelerometer data from ice bears, $37 \mathrm{~h}$ from captive polar bears, and $72 \mathrm{~h}$ from captive brown bears $U$. arctos. We identified 10 different behaviors from ice bears, with resting, walking, and eating being the most prevalent (Table 3). Ice bears ate recently killed adult, subadult, or pup ringed seals Pusa hispida, seal carcasses, bowhead whale Balaena mysticetus carcasses, or unidentifiable carcasses. Captive polar bears consumed fish, and captive brown bears ate dry omnivore chow. Captive brown bears also grazed on grass, which was excluded from analyses predicting behaviors of ice bears, but was included as eating for predicting behaviors of land bears.

Our models using an uneven distribution of behaviors in which we used $70 \%$ of each behavior from ice bears and all of the available data from captive polar or brown bears exhibited $5 \%$ greater predictive ability overall compared to the subsampled distribution, and $7 \%$ greater predictive ability overall compared to the balanced distribution based on F-measure (see Table S2 in the Supplement at www.int-res.com/articles/ suppl/n032p019_supp.pdf). In particular, the datasets with an uneven distribution exhibited greater ability to discriminate less frequent behaviors such as swimming, eating, and running (Table S2). Therefore, we used the datasets with uneven distributions for subsequent analyses (Table 3).

Our model with training data from ice bears had an OOB error rate of $2.0 \%$ and exhibited the greatest predictive abilities for all 10 behaviors (Fig. 2) compared to all other models tested. Our models with training data from captive polar bears and brown bears had OOB error rates of 3.7 and $0.5 \%$ respectively, indicating that both models performed well in discriminating captive behaviors. Both the ice
Table 3. Number of $2 \mathrm{~s}$ long behaviors used in random forest training datasets for predicting behaviors of wild polar bears Ursus maritimus. Ice bears: polar bears on the sea ice of the southern Beaufort Sea. Land bears: polar bears on Akimiski Island, Nunavut

\begin{tabular}{|lrrrr|}
\hline Behavior & $\begin{array}{c}\text { Captive } \\
\text { polar } \\
\text { bears }\end{array}$ & $\begin{array}{c}\text { Captive } \\
\text { brown } \\
\text { bears }\end{array}$ & $\begin{array}{c}\text { Wild } \\
\text { ice } \\
\text { bears }\end{array}$ & $\begin{array}{c}\text { Wild } \\
\text { land } \\
\text { bears }\end{array}$ \\
\hline Rest & 53656 & 104838 & 163301 & 43132 \\
Walk & 8962 & 33059 & 36083 & 958 \\
Swim & 423 & 0 & 703 & 0 \\
Eat & 2108 & 973 & 2100 & 1529 \\
Run & 0 & 0 & 943 & 0 \\
Pounce & 458 & 0 & 49 & 0 \\
Groom & 3729 & 432 & 1138 & 289 \\
Dig & 405 & 0 & 1194 & 0 \\
Head shake & 86 & 14 & 435 & 19 \\
Roll & 87 & 0 & 1473 & 0 \\
\hline
\end{tabular}

bear and captive polar bear models exhibited strong predictive ability for identifying resting and walking behaviors in wild bears $(>90 \% \mathrm{MCC}$, precision, recall, and F-measure; Table 4 \& Table S3 in the Supplement). Predictive abilities for other behaviors varied, with swimming and head shaking exhibiting strong predictive ability using the ice bear model (>75\% MCC, precision, recall, and F-measure), but lower predictive ability for eating, running, pouncing, grooming, digging, and rolling (Fig. 2, Tables 4 $\& 5)$. The model from ice bears had particularly greater ability than the captive polar bear model for

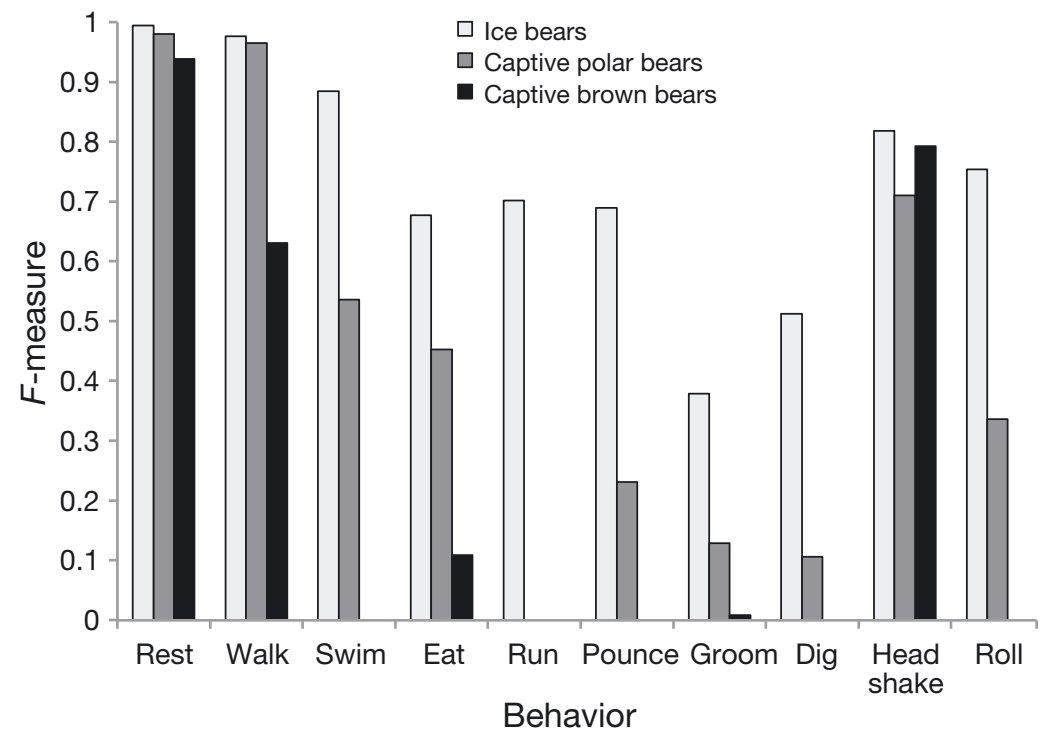

Fig. 2. Ability ( $F$-measure) of the random forest model to predict 10 behaviors of polar bears Ursus maritimus on the sea ice from 3 different training datasets of accelerometer data. Ice bears: polar bears on the sea ice of the southern Beaufort Sea 
Table 4. Performance of a random forest model using accelerometer data from polar bears Ursus maritimus on the sea ice to predict behaviors of bears on the sea ice as verified by video data. MCC: Matthews' correlation coefficient

\begin{tabular}{|lcccc|}
\hline Behavior & MCC & Precision & Recall & F-measure \\
\hline Rest & 0.973 & 0.992 & 0.997 & 0.994 \\
Walk & 0.971 & 0.964 & 0.989 & 0.976 \\
Swim & 0.887 & 0.957 & 0.823 & 0.885 \\
Eat & 0.674 & 0.677 & 0.677 & 0.677 \\
Run & 0.709 & 0.835 & 0.604 & 0.701 \\
Pounce & 0.700 & 0.833 & 0.588 & 0.690 \\
Groom & 0.417 & 0.658 & 0.266 & 0.379 \\
Dig & 0.532 & 0.712 & 0.400 & 0.513 \\
Head shake & 0.818 & 0.839 & 0.798 & 0.818 \\
Roll & 0.754 & 0.821 & 0.696 & 0.753 \\
\hline
\end{tabular}

swimming, pouncing, and digging (Fig. 2, Table S3). The captive brown bear model provided weaker ability to distinguish behaviors of ice bears for walking, eating, and grooming ( $<65 \% \mathrm{MCC}$ and $F$-measure), but reliably distinguished resting (Fig. 2, Table S4).

Using the model from ice bears, eating had a high rate of false positive classifications resulting from digging behavior being incorrectly classified as eating (Table 5) as well as a high rate of false negative classifications with eating behavior incorrectly classified as either resting or walking (Table 5). A post hoc test using only feeding behavior while eating a recently killed ringed seal within the training and testing datasets failed to improve our ability to discriminate eating $(\mathrm{MCC}=0.61$, precision $=0.67$, recall $=0.56, F$-measure $=0.61$ ). Additionally, running was often misclassified as walking, whereas rolling was often misclassified as resting (Table 5).

The most important predictors using the model from ice bears were static acceleration in the heave
(staticY) and surge directions (staticX), wet/dry conductivity (wetdry), and frequency at the dominant power spectrum in the surge direction (fdpsX; Fig. 3). Differences in the intensity of behaviors were discernible in the ODBA measures, with head shaking having the greatest ODBA and resting having the lowest (Table S5). Eating and swimming showed simi-

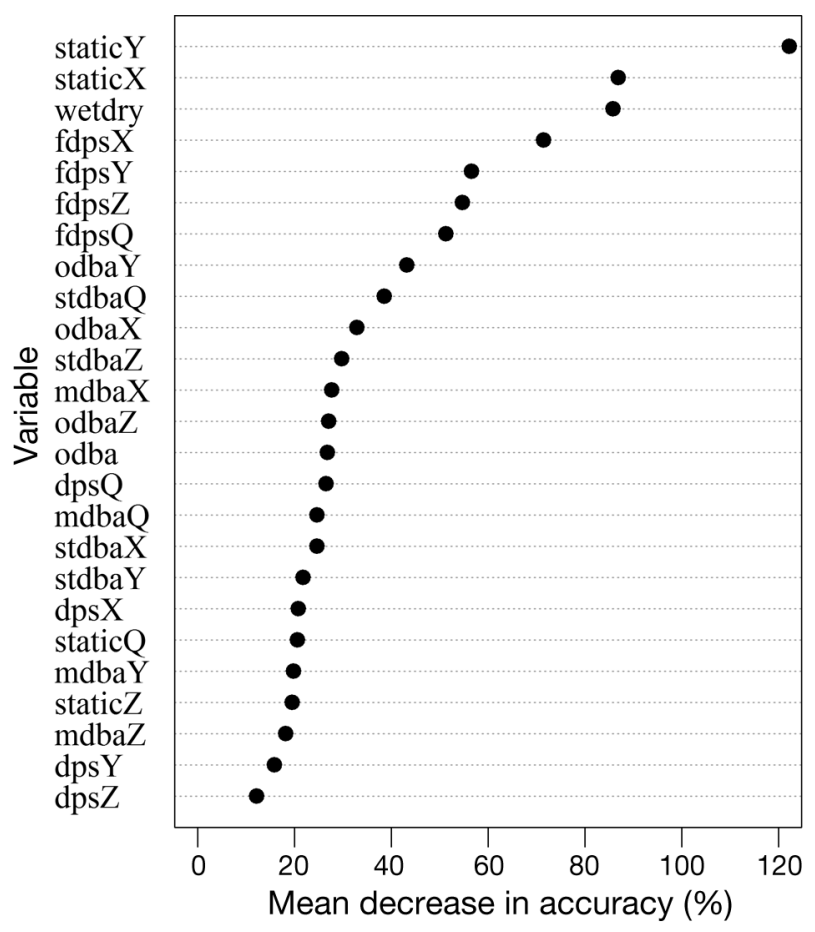

Fig. 3. Variable importance plot from the random forest model of accelerometer data from polar bears on the sea ice. The importance plot provides a relative ranking of parameters in which higher values indicate parameters that contributed more toward classification accuracy. Mean decrease in accuracy is normalized by dividing by the standard errors of the parameters (i.e. $z$-score). See Table 2 for description of parameters

Table 5. Cross-validation comparing predicted behaviors (rows) from accelerometer analyses of polar bears Ursus maritimus on the sea ice to actual behaviors (columns) confirmed by video recordings. Correct classifications are denoted in bold. See Table 4 for performance statistics in predicting behaviors

\begin{tabular}{|c|c|c|c|c|c|c|c|c|c|c|}
\hline & Rest & Walk & Swim & Eat & Run & Pounce & Groom & Dig & Head shake & Roll \\
\hline Rest & 69760 & 31 & 33 & 99 & 1 & 0 & 281 & 28 & 0 & 111 \\
\hline Walk & 115 & 15295 & 10 & 111 & 153 & 4 & 15 & 102 & 26 & 41 \\
\hline Swim & 6 & 2 & 246 & 1 & 0 & 0 & 1 & 0 & 0 & 1 \\
\hline Eat & 35 & 51 & 2 & 608 & 1 & 0 & 45 & 145 & 0 & 11 \\
\hline Run & 0 & 44 & 0 & 1 & 243 & 0 & 0 & 1 & 1 & 1 \\
\hline Pounce & 0 & 0 & 0 & 0 & 0 & 10 & 0 & 2 & 0 & 0 \\
\hline Groom & 17 & 2 & 0 & 33 & 0 & 0 & 129 & 13 & 0 & 2 \\
\hline Dig & 2 & 16 & 0 & 44 & 0 & 2 & 9 & 203 & 0 & 9 \\
\hline Head shake & 2 & 6 & 0 & 0 & 3 & 0 & 0 & 2 & 146 & 15 \\
\hline Roll & 45 & 13 & 8 & 1 & 1 & 1 & 5 & 2 & 10 & 437 \\
\hline
\end{tabular}


lar mean ODBA values, but had differing mean static acceleration values (Table S5). Eating and grooming had low values of static acceleration in the heave direction (staticY), which was indicative of a head-down posture. Walking and running exhibited periodic undulating patterns in static acceleration in the heave direction (staticY; Fig. 4 \& Fig. S1 in the Supplement), which was indicative of the bear's head moving up and down as it stepped. Wet/dry conductivity while swimming was lower for wild polar bears $(\bar{x}=81.9, \mathrm{SD}$ $=81.5)$ than captive polar bears $(\bar{x}=205.3, \mathrm{SD}=57.8)$ and lower than all other behaviors (all $\bar{x}>234$ ). A post hoc test excluding the conductivity variable reduced the ability of the algorithm to correctly identify swimming behaviors using the training dataset for ice bears $(\mathrm{MCC}=0.47$, precision $=0.77$, recall $=0.29, F$ measure $=0.42$ ) with a high rate of swimming behaviors misclassified as resting.

\section{Behaviors on land}

Video collars on land bears recorded 19 to $36 \mathrm{~h}$ of video $(\bar{x}=27 \mathrm{~h}, \mathrm{SD}=12 \mathrm{~h}, \mathrm{n}=2)$ and in total we collected $36 \mathrm{~h}$ of video-linked accelerometer data for the behaviors of interest. We identified 5 different behaviors from land bears, with resting being the most prevalent, followed by eating (Table 3). Eating on land consisted of berries, primarily crowberries Empetrum nigrum.

Our model with training data from land bears had an OOB error rate of $0.5 \%$ and had the greatest success in discriminating on-land behaviors (Fig. 5, Table S6). All behaviors, except for grooming and head shaking, had $\mathrm{MCC}$, precision, recall, and Fmeasure values $>90 \%$ using the model from land bears (Fig. 5, Table S6). In particular, the model from land bears was able to distinguish eating ( $\mathrm{MCC}=$ 0.95, , precision $=0.95$, recall $=0.96, F$-measure $=$ 0.95), which was not possible with the other datasets. Our model with training data from ice bears had success in discriminating resting behaviors on land $(\mathrm{MCC}=0.60$, precision $=0.96$, recall $=1.0, F$-measure $=0.98)$ and walking on land $(\mathrm{MCC}=0.82$, precision $=0.89$, recall $=0.76, F$-measure $=0.82$ ), but eating was often misclassified as resting or walking (FP). The captive polar bear model performed similarly to the model from ice bears for discriminating behaviors on land (Fig. 5). The captive brown bear model performed less well than the other models for discriminating walking on land, but otherwise performed similarly to the models from ice bears and captive polar bears (Fig. 5).

\section{Sampling frequency}

The OOB error rate using the data from ice bears increased from 2.0 to $2.2 \%$ using an $8 \mathrm{~Hz}$ sampling frequency and to $2.6 \%$ using a $4 \mathrm{~Hz}$ sampling frequency. OOB error rate using data from land bears increased from 0.5 to $0.6 \%$ at $8 \mathrm{~Hz}$ and to $0.8 \%$ at $4 \mathrm{~Hz}$. Predictive ability using an $8 \mathrm{~Hz}$ sampling frequency was nearly identical to $16 \mathrm{~Hz}$ among all behaviors using the dataset from ice bears $\left(t_{58}=0.70, \mathrm{p}=0.24\right)$ and land bears $\left(t_{28}=0.61, \mathrm{p}=0.27\right)$ based on MCC, precision, and recall. Predictive ability using a $4 \mathrm{~Hz}$ sampling frequency was lower than predictive ability using $16 \mathrm{~Hz}$ for ice bears $\left(t_{55}=1.8, \mathrm{p}=0.04\right)$, but not for land bears $\left(t_{27}=0.59, \mathrm{p}=0.28\right)$. In particular, the ability to discriminate the high intensity behaviors of pouncing and head shaking declined using a $4 \mathrm{~Hz}$ sampling rate (Fig. 6).

\section{DISCUSSION}

Our results show that tri-axial accelerometers in combination with measures of conductivity can reliably distinguish the 3 most common behaviors of wild polar bears Ursus maritimus (resting, walking, and swimming; Stirling 1974, Latour 1981, Hansson \& Thomassen 1983, Lunn \& Stirling 1985). This will provide a method to remotely document the activity budgets of these far-ranging animals, which can be further linked with location data from satellite collars to examine the effects of habitat on behavior and energy expenditure. Our results indicate that differences among habitats and species can impact the ability to discriminate behaviors in wild individuals using accelerometers. We found no loss in predictive ability using an $8 \mathrm{~Hz}$ sampling frequency, which would allow for twice the battery longevity of a $16 \mathrm{~Hz}$ rate and reduce the computational power needed for analyses. Although accelerometer studies on smaller species appear to require greater sampling frequencies (e.g. >30 Hz; Broell et al. 2013, Brown et al. 2013), our results are similar to data obtained by Rekvik (2015) from captive brown bears U. arctos, and by Wang et al. (2015) from captive mountain lions Puma concolor, which both found little loss in predictive ability at sampling frequencies $\geq 8 \mathrm{~Hz}$.

\section{Habitat effects}

Our results indicate that accelerometer signatures on sea ice are similar to signatures on land for most 


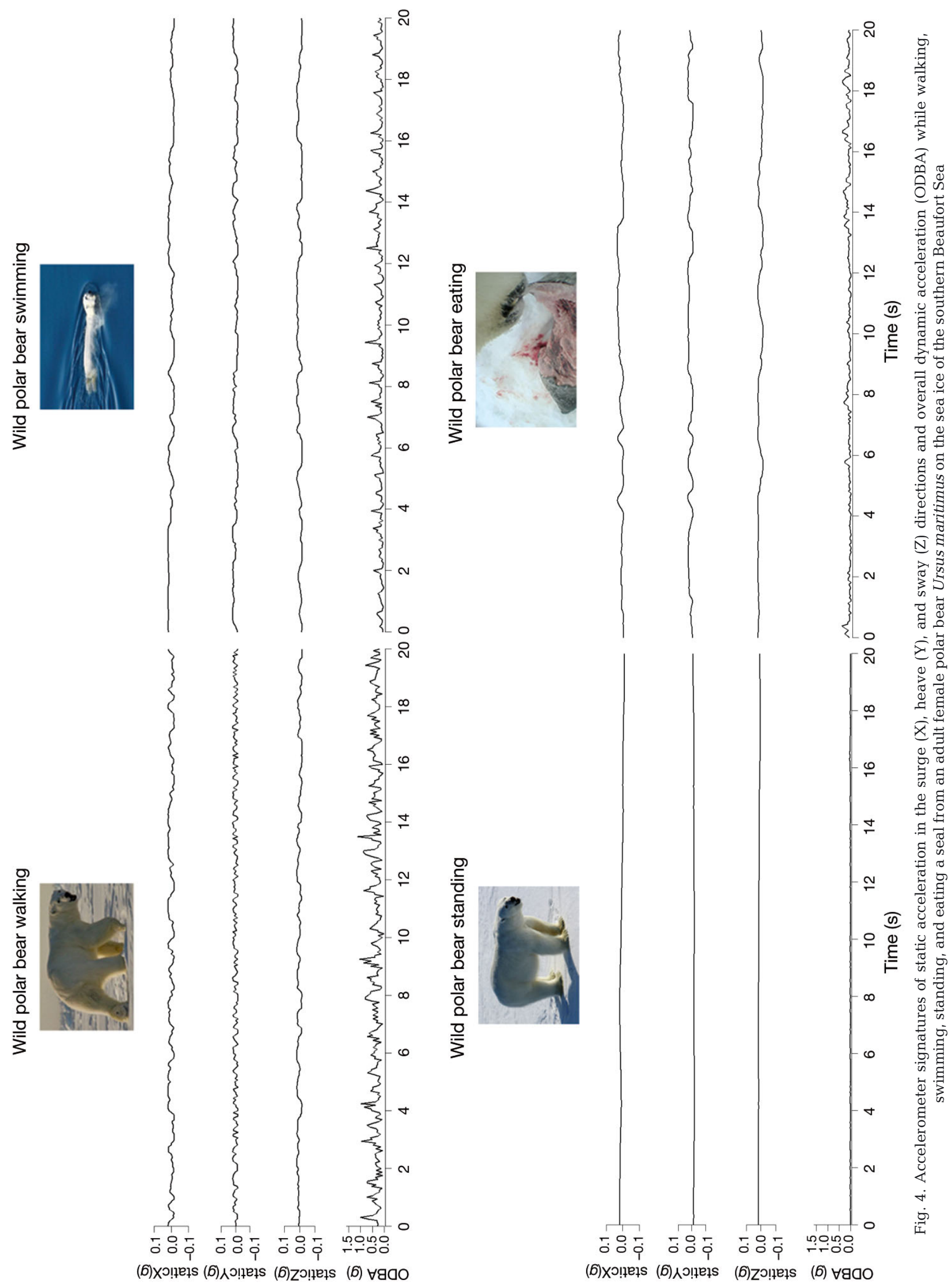




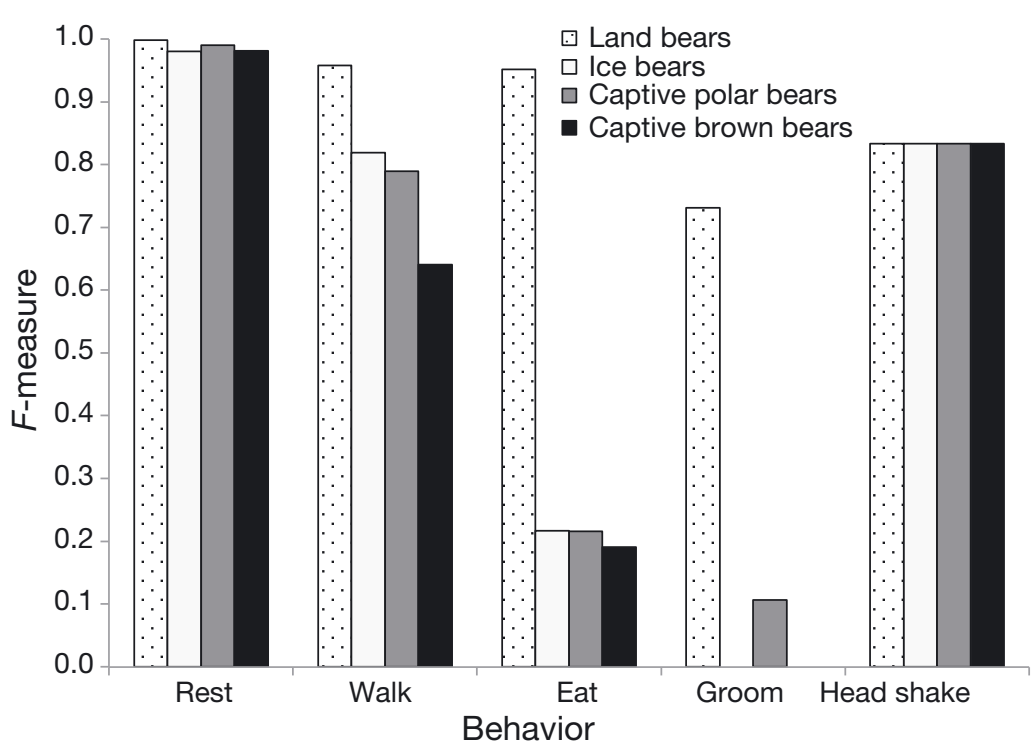

Fig. 5. Ability ( $F$-measure) of a random forest model to predict behaviors of polar bears Ursus maritimus on land from 4 different training datasets. Ice bears: polar bears on the the sea ice of the southern Beaufort Sea. Land bears: polar bears on Akimiski Island, Nunavut

behaviors, but eating berries by land bears had a distinct signature that our ice bear model and captive bear models misclassified as grooming, resting, or walking. This highlights the value in linking observational and accelerometer data from wild subjects over multiple time periods and habitats, and the importance of accounting for as many behaviors as possible in training datasets. Knowledge of eating frequency and duration would provide insight in determining foraging success, an important determi- nant of individual reproductive success and survival (Stirling et al. 1999, Regehr et al. 2007, 2010). Although we had success discriminating eating events by land bears, we had lower precision and recall in discriminating eating events by ice bears. This was likely related in part to the movement pattern of bears eating berries, in which they typically stood with their head down and grazed. Conversely, bears eating on the sea ice exhibited a variety of positions including standing, sitting, and lying down, and both tore pieces of food from seals or gnawed on carcasses. Since most kill events involve bears pouncing on their seal prey (Stirling 1988, Derocher 2012), we may be able to identify successful kills based on the combination of a pouncing signature followed by eating signatures (e.g. Williams et al. 2014), but this requires further evaluation. Additionally, feeding on a seal would typically last for a prolonged period; hence, if the model primarily predicted eating over a prolonged period this could be used as an indication of a feeding event, but this also requires further evaluation.

\section{Use of captive animals and surrogate species}

Our ability to discriminate behaviors was greatly improved by including data from free-ranging polar

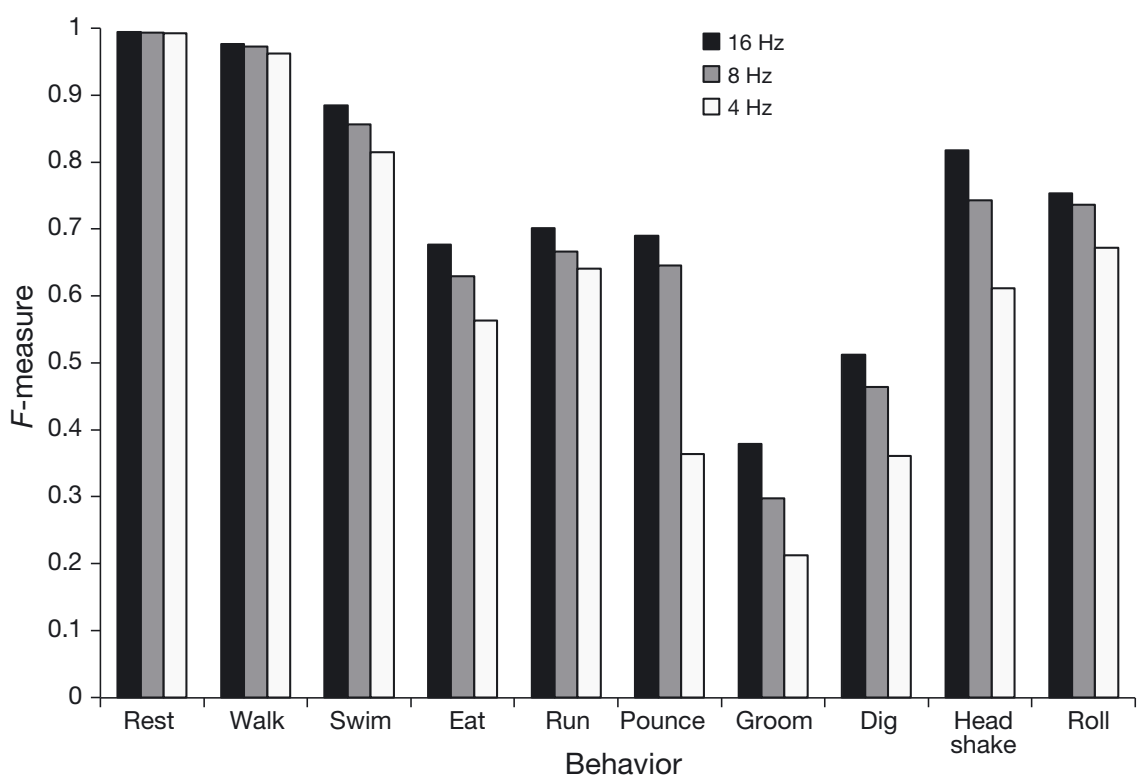

Fig. 6. Ability (F-measure) of a random forest model to predict behaviors of polar bears Ursus maritimus on the sea ice using 3 different accelerometer sampling frequencies 
bears rather than using data from captive bears alone. However, resting and walking could be reliably discriminated using data from either captive or wild polar bears. This illustrates the value of collecting data from captive individuals when data collection is difficult or impossible from wild counterparts. However, data from captive brown bears exhibited poorer performance for predicting active behaviors in wild polar bears. This may be related to differences in walking kinematics between polar and brown bears as well as potential differences in limb lengths between the species (Renous et al. 1998). Additionally, polar bears have longer necks relative to their body size than other ursid species (DeMaster \& Stirling 1981), which could also affect accelerometer signatures from a neck-worn collar. Although Campbell et al. (2013) proposed the use of surrogate species to predict the behaviors of other species, our findings suggest that polar bear accelerometer signatures are likely species- and habitat-specific, at least for distinguishing specific behaviors. The brown bear model did reliably distinguish resting behavior in wild polar bears, which suggests that surrogate species could be used to distinguish coarse activity patterns such as active versus inactive (e.g. Gervasi et al. 2006, Ware et al. 2015).

Our analyses indicate that conductivity measures are needed to reliably discriminate swimming. Greater conductivity measures in captive polar bears that were swimming in fresh water likely caused the poorer performance for discriminating swimming in wild polar bears that were swimming in salt water. For pouncing, captive polar bears pounced on large plastic barrels, which resulted in similar measures of ODBA as wild counterparts, but had different signatures of static acceleration (i.e. body posture). Digging by wild bears, which was often through snow and ice into subnivean lairs to locate seals, exhibited greater ODBA measures and slightly different static acceleration than captive bears digging in snow and ice. These results suggest that some behaviors of captive bears may not fully reflect behaviors of their wild counterparts, which further illustrates the value of collecting simultaneous observational data (e.g. video) from free-ranging individuals to calibrate accelerometer-based behavioral data.

\section{Accelerometer attachment}

Regardless of which training dataset was used, we found lower precision and recall for predicting 5 of the behaviors tested for bears on the sea ice.
Eating, grooming, and rolling had high rates of misclassifications as resting, whereas running and digging had high rates of misclassifications as walking. These results suggest the random forest algorithm could be prone to slightly overestimate the amount of true resting and walking behaviors in quantifying activity budgets. Our lower precision and recall for discriminating some behaviors was likely due in part to the attachment of the accelerometer on a collar. Although a number of studies have successfully discriminated behaviors using accelerometers on collars (Watanabe et al. 2005, Martiskainen et al. 2009, Soltis et al. 2012, McClune et al. 2014, Lush et al. 2015, Rekvik 2015, Wang et al. 2015), many of these studies limited their analyses to 4 or 5 behaviors or documented high misclassification rates for distinguishing some behaviors. Wang et al. (2015) similarly reported low accuracy of accelerometers on collars for predicting eating and grooming by captive mountain lions, and Lush et al. (2015) reported low accuracy for predicting some behaviors, including grooming, in wild brown hares Lepus europaeus. Attachment of the accelerometer to a collar, as opposed to attachment directly on the animal, likely introduces noise in the data due to independent collar motion (i.e. the collar must be fitted to ensure animals do not remove it, but loose enough to accommodate potential changes in body mass) and may reduce the ability of the accelerometer to detect some low intensity movements (Shepard et al. 2008). The effect of independent collar motion is evident in our large values of ODBA when bears shook their heads. This behavior may be useful for identifying the end of a swim, as bears are known to shake and roll in the snow following a swim. Additionally, our ability to discriminate head shaking allows for excluding it from potential energetic analyses using accelerometers. Use of a higher sampling frequency than was used in this study (i.e. $>16 \mathrm{~Hz}$ ) could potentially improve the ability to discriminate some fine-scale body movements (Nathan et al. 2012) such as eating, though Wang et al. (2015) sampled at $64 \mathrm{~Hz}$ and had low accuracy in discriminating eating behaviors of captive mountain lions.

\section{Video calibration}

Having video-linked observational data from camera-mounted collars on wild polar bears was the most practical method to calibrate accelerometers on freeranging individuals. However, because the animal's 
body was not visible in the video, some behaviors may have been incorrectly classified. For example, distinguishing walking versus running was often challenging, as was determining when bears were actively swimming versus resting in the water. Both of these could have contributed to the misclassifications between running and walking and swimming and resting. Additionally, the models had greater success discriminating behaviors as sample sizes increased. Although unbalanced datasets are known to affect the predictive ability of random forest algorithms (Chen et al. 2004), we found that the inclusion of larger sample sizes in the training dataset was more important than imbalance. This highlights the value of calibrating accelerometers from multiple individuals over prolonged periods.

\section{CONCLUSIONS}

Our results underscore the importance of thoroughly validating accelerometers for use in remote detection of behavior, ideally on a species- and habitat-specific level. The use of tri-axial accelerometers, as shown here, will enable detailed assessments of polar bear behaviors to better understand polar bear habitat use and the implications for energy demands. For example, measures of acceleration could be combined with measures of oxygen consumption from captive bears while resting, walking, and swimming to both quantify activity budgets and estimate the energetic costs of these behaviors (e.g. Wilson et al. 2006, 2012, Halsey et al. 2009, 2011, Gómez Laich et al. 2011, Williams et al. 2014). Future advances are needed that would enable remote transmission of raw accelerometer data to further enhance the applicability of these devices to animals occurring in remote environments and obviate the need for sensor recovery. As declines in sea ice are expected to increase the activity rates of polar bears across much of their range (Derocher et al. 2004, Molnár et al. 2010, Sahanatien \& Derocher 2012), the use of accelerometers provides a method to monitor the impacts of habitat change on activity and energy budgets to better understand the implications for body condition, reproductive success, and survival of this Arctic apex predator.

Acknowledgements. Procedures were approved by the Animal Care and Use Committees of the University of California, Santa Cruz; Washington State University; York University; Oregon Zoo; Alaska Zoo; San Diego Zoo; Ontario Ministry of Natural Resources and Forestry; and the US
Geological Survey, Alaska Science Center. Research in the USA was permitted under US Fish and Wildlife Service permits MA690038 and MA95406A. Research on Akimiski Island, Nunavut was approved under Nunavut Wildlife Research Permit WL 2015-073. This work was supported by US Geological Survey's Changing Arctic Ecosystems Initiative. Additional support was provided by Polar Bears International; World Wildlife Fund (Canada); Ontario Ministry of Natural Resources and Forestry; Natural Sciences and Engineering Research Council of Canada; Born Free Foundation; Helen McCrea Peacock Foundation; Institute for Conservation Research, San Diego Zoo Global; and the International Association for Bear Research and Management. Support for T.M.W. was provided by the National Science Foundation's Instrument Development for Biological Research program. We thank Mehdi Bakhtiari (Exeye) for developing the video collars used in this study. We thank the bear keeper and trainer teams at the Oregon Zoo, San Diego Zoo, and Alaska Zoo for enabling data collection at their facilities. We thank Stephen Atkinson, Tyrone Donnelly, Katie Florko, Sarah Hagey, Tim Moody, Kristin Simac, and Maria Spriggs for assistance in the field. We thank helicopter pilots Frank Ross (Soloy Helicopters) and Doug Holtby (OMNRF) for field support. B. Battaile and 3 anonymous reviewers provided valuable input on earlier versions of the manuscript. This research used resources of the Core Science Analytics and Synthesis Applied Research Computing program at the US Geological Survey. Use of trade names is for descriptive purposes only and does not imply endorsement by the US Government. This paper was reviewed and approved by the USGS under its Fundamental Science Practices policy (www.usgs.gov/fsp).

\section{LITERATURE CITED}

Alvarenga FAP, Borges I, Palkovi L, Rodina J, Oddy VH, Dobos RC (2016) Using a three-axis accelerometer to identify and classify sheep behaviour at pasture. Appl Anim Behav Sci 181:91-99

Amstrup SC, Marcot BG, Douglas DC (2008) A Bayesian network modeling approach to forecasting the $21^{\text {st }}$ century worldwide status of polar bears. In: DeWeaver ET, Blitz CM, Tremblay LB (eds) Arctic sea ice decline: observations, projections, mechanisms, and implications. Geophysics Monograph Series 180. American Geophysical Union, Washington, DC, p 213-268

* Atwood TC, Marcot BG, Douglas DC, Amstrup SC, Rode KD, Durner GM, Bromaghin JF (2016) Forecasting the relative influence of environmental and anthropogenic stressors on polar bears. Ecosphere 7:e01370

Basu I, Graupe D, Tuninetti D, Shukla P, Slavin KV, Metman LV, Corcos DM (2013) Pathological tremor prediction using surface EMG and acceleration: potential use in 'ON-OFF' demand driven deep brain stimulator design. J Neural Eng 10:036019

Bidder OR, Qasem LA, Wilson RP (2012) On higher ground: How well can dynamic body acceleration determine speed in variable terrain? PLOS ONE 7:e50556

*Bograd SJ, Block BA, Costa DP, Godley BJ (2010) Biologging technologies: new tools for conservation. Introduction. Endang Species Res 10:1-7

Breiman L (2001) Random forests. Mach Learn 45:5-32

* Broell F, Noda T, Wright S, Domenici P, Steffensen JF, Auclair JP, Taggart CT (2013) Accelerometer tags: de- 
tecting and identifying activities in fish and the effect of sampling frequency. J Exp Biol 216:1255-1264

Bromaghin JF, McDonald TL, Stirling I, Derocher AE and others (2015) Polar bear population dynamics in the southern Beaufort Sea during a period of sea ice decline. Ecol Appl 25:634-651

Brown DD, Kays R, Wikelski M, Wilson R, Klimley AP (2013) Observing the unwatchable through acceleration logging of animal behavior. Anim Biotelem 1:20

Campbell HA, Gao L, Bidder OR, Hunter J, Franklin CE (2013) Creating a behavioural classification module for acceleration data: using captive surrogate for difficult to observe species. J Exp Biol 216:4501-4506

* Caro T (1999) The behavior-conservation interface. Trends Ecol Evol 14:366-369

Cattet MRL, Caulkett NA, Polischuk SC, Ramsay MA (1997) Reversible immobilization of free-ranging polar bears with medetomidine-zolazepam-tiletamine and atipamezole. J Wildl Dis 33:611-617

Chen C, Liaw A, Breiman L (2004) Using random forest to learn imbalanced data. University of California, Berkeley, CA. http://statistics.berkeley.edu/sites/default/files/ tech-reports/666.pdf (accessed Oct 2015)

Cooke SJ (2008) Biotelemetry and biologging in endangered species research and animal conservation: relevance to regional, national, and IUCN Red List threat assessments. Endang Species Res 4:165-185

Cooke SJ, Blumstein DT, Buchholz R, Caro T and others (2014) Physiology, behavior, and conservation. Physiol Biochem Zool 87:1-14

Costa DP, Huckstadt LA, Crocker DE, McDonald BI, Goebel ME, Fedak MA (2010) Approaches to studying climate change and its role on the habitat selection of Antarctic pinnipeds. Integr Comp Biol 50:1018-1030

DeMaster DP, Stirling I (1981) Ursus maritimus. Mamm Species 145:1-7

Derocher AE (2012) Polar bears: a complete guide to their biology and behavior. Johns Hopkins University Press, Baltimore, MD

* Derocher AE, Lunn NJ, Stirling I (2004) Polar bears in a warming climate. Integr Comp Biol 44:163-176

* Durner GM, Douglas DC, Nielson RM, Amstrup SC and others (2009) Predicting 21st-century polar bear habitat distribution from global climate models. Ecol Monogr 79: 25-58

Ferguson SH, Taylor MK, Messier F (2000) Influence of sea ice dynamics on habitat selection by polar bears. Ecology 81:761-772

Gervasi V, Brunberg S, Swenson JE (2006) An individualbased method to measure animal activity levels: a test on brown bears. Wildl Soc Bull 34:1314-1319

Gómez Laich A, Wilson RP, Gleiss AC, Shepard ELC, Quintana F (2011) Use of overall dynamic body acceleration for estimating energy expenditure in cormorants: Does locomotion in different media affect relationships? J Exp Mar Biol Ecol 399:151-155

Gaf PM, Wilson RP, Qasem L, Hackländer K, Rosell F (2015) The use of acceleration to code for animal behaviours; a case study in free-ranging Eurasian beavers Castor fiber. PLOS ONE 10:e0136751

Halsey LG, Green JA, Wilson RP, Frappell PB (2009) Accelerometry to estimate energy expenditure during activity: best practice with data loggers. Physiol Biochem Zool 82:396-404

*Halsey LG, Shepard ELC, Wilson RP (2011) Assessing the development and application of the accelerometry technique for estimating energy expenditure. Comp Biochem Physiol A Mol Integr Physiol 158:305-314

*Hammond TT, Springthorpe D, Walsh RE, Berg-Kirkpatrick $\mathrm{T}$ (2016) Using accelerometers to remotely and automatically characterize behavior in small animals. J Exp Biol 219:1618-1624

Hansson R, Thomassen J (1983) Behavior of polar bears with cubs in the denning area. Int Conf Bear Res Manage 5: $246-254$

*Hunter CM, Caswell H, Runge MC, Regehr EV, Amstrup SC, Stirling I (2010) Climate change threatens polar bear populations: a stochastic demographic analysis. Ecology 91:2883-2897

Kalxdorff SB (1997) Collection of local knowledge regarding polar bear habitat use in Alaska. US Fish and Wildlife Service Tech Rep MMM 87-2. Marine Mammals Management, US Fish and Wildlife Service, Anchorage, AK

Knudsen B (1978) Time budgets of polar bears (Ursus maritimus) on North Twin Island, James Bay, during summer. Can J Zool 56:1627-1628

Kochnev AA, Etylin VM, Kavry VI, Siv-Siv EB, Tanko IV (2003) Traditional knowledge of Chukotka Native peoples regarding polar bear habitat use. Final Report. Prepared for the US National Park Service, Chukotka Association of Traditional Marine Mammal Hunters, Alaska Nanuuq Commission, and Pacific Fisheries Research Center (Chukotka Branch), Anchorage, AK

* Latour PB (1981) Spatial relationships and behavior of polar bears (Ursus maritimus Phipps) concentrated on land during the ice-free season of Hudson Bay. Can J Zool 59: 1763-1774

Liaw A, Wiener M (2002) Classification and regression by randomForest. R News 2/3:18-22

Lunn NJ, Stirling I (1985) The significance of supplemental food to polar bears during the ice-free period of Hudson Bay. Can J Zool 63:2291-2297

* Lush L, Ellwood S, Markham A, Ward AI, Wheeler P (2015) Use of tri-axial accelerometers to assess terrestrial mammal behavior in the wild. J Zool (Lond) 298:257-265

Martins M, Santos C, Costa L, Frizera A (2016) Feature reduction and multi-classification of different assistive devices according to the gait pattern. Disabil Rehabil Assist Technol 11:202-218

*Martiskainen P, Järvinen M, Skön JP, Tiirikainen J, Kolehmainen M, Mononen J (2009) Cow behaviour pattern recognition using three-dimensional accelerometer and support vector machines. Appl Anim Behav Sci 119: 32-38

Matthews BW (1975) Comparison of the predicted and observed secondary structure of T4 phage lysozyme. Biochim Biophys Acta 405:442-451

*Mauritzen M, Belikov SE, Boltunov AN, Derocher AE and others (2003) Functional response in polar bear habitat selection. Oikos 100:112-124

McClune DW, Marks NJ, Wilson RP, Houghton JDR and others (2014) Tri-axial accelerometers quantify behaviour in the Eurasian badger (Meles meles): towards an automated interpretation of field data. Anim Biotelem 2:5

McClune DW, Marks NJ, Delahay RJ, Montgomery WI, Scantlebury DM (2015) Behavior-time budget and functional habitat use of free-ranging European badger (Meles meles). Anim Biotelem 3:7 
McPhee ME, Carlstead K (2010) The importance of maintaining natural behaviors in captive mammals. In: Kleiman DG, Thompson KV, Baer CK (eds) Wild mammals in captivity: principles and techniques for zoo management, $2^{\text {nd }}$ edn. University of Chicago Press, Chicago, IL, p 303-313

Molnár PK, Derocher AE, Thiemann GW, Lewis MA (2010) Predicting survival, reproduction and abundance of polar bears under climate change. Biol Conserv 143: 1612-1622

Nakamura I, Goto Y, Sato K (2015) Ocean sunfish rewarm at the surface after deep excursions to forage for siphonophores. J Anim Ecol 84:590-603

Nathan R, Spiegel O, Fortmann-Roe S, Harel R, Wikelski M, Getz WM (2012) Using tri-axial acceleration data to identify behavioral modes of free-ranging animals: general concepts and tools illustrated for griffon vultures. J Exp Biol 215:986-996

Nelson RK (1966) Alaska Eskimo exploitation of the sea ice environment. Arctic Aeromedical Laboratory, Fort Wainwright, AK

* Obbard ME, Cattet MRL, Howe EJ, Middel KR and others (2016) Trends in body condition in polar bears (Ursus maritimus) from the Southern Hudson Bay subpopulation in relation to changes in sea ice. Arctic Sci 2:15-32

R Core Team (2014) R: a language and environment for statistical computing. R Foundation for Statistical Computing, Vienna

Regehr EV, Lunn NJ, Amstrup SC, Stirling I (2007) Effects of earlier sea ice breakup on survival and population size of polar bears in western Hudson Bay. J Wildl Manag 71: 2673-2683

Regehr EV, Hunter CM, Caswell H, Amstrup SC, Stirling I (2010) Survival and breeding of polar bears in the southern Beaufort Sea in relation to sea ice. J Anim Ecol 79: $117-127$

Rekvik GES (2015) Identification of five brown bear (Ursus arctos) behaviors using tri-axial accelerometers. MSc thesis, Telemark University College

Renous S, Gasc JP, Abourachid A (1998) Kinematic analysis of the locomotion of the polar bear (Ursus maritimus, Phipps, 1774) in natural and experimental conditions. Neth J Zool 48:145-167

Resheff YS, Rotics S, Harel R, Spiegel O, Nathan R (2014) AcceleRater: a web application for supervised learning of behavioral modes from acceleration measurements. Mov Ecol 2:27

Rode KD, Amstrup SC, Regehr EV (2010) Reduced body size and cub recruitment in polar bears associated with sea ice decline. Ecol Appl 20:768-782

Rode KD, Peacock E, Taylor M, Stirling I, Born EW, Laidre KL, Wiig $\varnothing$ (2012) A tale of two polar bear populations: ice habitat, harvest, and body condition. Popul Ecol 54: 3-18

Ropert-Coudert Y, Wilson RP (2005) Trends and perspectives in animal-attached remote sensing. Front Ecol Environ 3:437-444

Sahanatien V, Derocher AE (2012) Monitoring sea ice habitat fragmentation for polar bear conservation. Anim Conserv 15:397-406

Schweinsburg RE, Lee LJ (1982) Movement of four satellitemonitored polar bears in Lancaster Sound, Northwest Territories. Arctic 35:504-511

Shamoun-Baranes J, Bom R, van Loon EE, Ens BJ, Oosterbeek K, Bouten W (2012) From sensor data to animal behaviour: an oystercatcher example. PLOS ONE 7: e37997

Shepard ELC, Wilson RP, Quintana F, Gómez Laich A and others (2008) Identification of animal movement patterns using tri-axial accelerometry. Endang Species Res 10: 47-60

Shepard ELC, Wilson RP, Rees WG, Grundy E, Lambertucci SA, Vosper SB (2013) Energy landscapes shape animal movement ecology. Am Nat 182:298-312

Soltis J, Wilson RP, Douglas-Hamilton I, Vollrath F, King LE, Savage A (2012) Accelerometers in collars identify behavioral states in captive African elephants Loxodonta africana. Endang Species Res 18:255-263

Stirling I (1974) Midsummer observations on the behavior of wild polar bears (Ursus maritimus). Can J Zool 52: 1191-1198

Stirling I (1988) Polar bears. University of Michigan Press, Ann Arbor, MI

Stirling I, Latour PB (1978) Comparative hunting abilities of polar bear cubs of different ages. Can J Zool 56: 1768-1772

Stirling I, Spencer C, Andriashek D (1989) Immobilization of polar bears (Ursus maritimus) with Telazol ${ }^{\circ}$ in the Canadian Arctic. J Wildl Dis 25:159-168

Stirling I, Lunn NJ, Iacozza J (1999) Long-term trends in the population ecology of polar bears in western Hudson Bay in relation to climatic change. Arctic 52:294-306

Stirling I, Spencer C, Andriashek D (2016) Behavior and activity budgets of wild breeding polar bears (Ursus maritimus). Mar Mamm Sci 32:13-37

* Sutherland WJ (1998) The importance of behavioral studies in conservation biology. Anim Behav 56:801-809

Taylor MK (1986) Movements of Alaskan polar bears instrumented with satellite transmitters. Int Conf Bear Res Manage 6:103-104

* Teisberg JE, Farley SD, Lynne Nelson O, Hilderbrand GV and others (2014) Immobilization of grizzly bears (Ursus arctos) with dexmedetomidine, tiletamine, and zolazepam. J Wildl Dis 50:74-83

Volpov BL, Hoskins AJ, Battaile BC, Viviant M and others (2015) Identification of prey captures in Australian fur seals (Arctocephalus pusillus doriferus) using headmounted accelerometers: field validation with animalborne video cameras. PLOS ONE 10:e0128789

Vongraven D, Aars J, Amstrup S, Atkinson SN and others (2012) A circumpolar monitoring framework for polar bears. Ursus 23:1-66

Voorhees H, Sparks R, Huntington HP, Rode KD (2014) Traditional knowledge about polar bears (Ursus maritimus) in northwestern Alaska. Arctic 67:523-536

WWang Y, Nickel B, Rutishauser M, Bryce C, Williams TM, Elkaim G, Wilmers CC (2015) Movement, resting, and attack behaviors of wild pumas are revealed by tri-axial accelerometer measurements. Mov Ecol 3:2

*Ware JV, Rode KD, Pagano AM, Bromaghin J and others (2015) Validation of mercury tip-switch and accelerometer activity sensors for identifying resting and active behavior in bears. Ursus 26:86-96

Watanabe YY, Takahashi A (2013) Linking animal-borne video to accelerometers reveals prey capture variability. Proc Natl Acad Sci USA 110:2199-2204

Watanabe S, Izawa M, Kato A, Ropert-Coudert Y, Naito Y (2005) A new technique for monitoring the detailed behaviour of terrestrial animals: a case study with the domestic cat. Appl Anim Behav Sci 94:117-131 
Williams TM (1983) Locomotion in the North American mink, a semi-aquatic mammal. I. Swimming energetics and body drag. J Exp Biol 103:155-168

Williams TM, Wolfe L, Davis T, Kendall T and others (2014) Instantaneous energetics of puma kills reveal advantage of felid sneak attacks. Science 346:81-85

Wilmers CC, Nickel B, Bryce CM, Smith JA, Wheat RE, Yovovich V (2015) The golden age of bio-logging: how animal-borne sensors are advancing the frontiers of ecology. Ecology 96:1741-1753

Wilson RP, White CR, Quintana F, Halsey LG, Liebsch N, Martin GR, Butler PJ (2006) Moving towards acceleration for estimates of activity-specific metabolic rate in freeliving animals: the case of the cormorant. J Anim Ecol 75: 1081-1090

Wilson RP, Shepard ELC, Liebsch N (2008) Prying into the

Editorial responsibility: Rory Wilson,

Swansea, UK intimate details of animal lives: use of a daily diary on animals. Endang Species Res 4:123-137

* Wilson RP, Quintana F, Hobson VJ (2012) Construction of energy landscapes can clarify the movement and distribution of foraging animals. Proc R Soc B 279:975-980

WWilson RR, Horne JS, Rode KD, Regehr EV, Durner GM (2014) Identifying polar bear resource selection patterns to inform offshore development in a dynamic and changing Arctic. Ecosphere 5:136

* Yoda K, Sato K, Niizuma Y, Kurita M, Bost CA, Le Maho Y, Naito Y (1999) Precise monitoring of porpoising behaviour of Adélie penguins determined using acceleration data loggers. J Exp Biol 202:3121-3126

*Yoda K, Naito Y, Sato K, Takahashi A and others (2001) A new technique for monitoring the behaviour of freeranging Adélie penguins. J Exp Biol 204:685-690

Submitted: April 25, 2016; Accepted: October 13, 2016 Proofs received from author(s): December 3, 2016 